\title{
Milliliter per Square Meter per Day
}

National Cancer Institute

\section{Source}

National Cancer Institute. Milliliter per Square Meter per Day. NCI Thesaurus. Code C66977.

A dose calculation unit expressed in milliliter(s) per square meter per period of time equal to twenty-four hours. 